\title{
ILUSÕES DE MODERNIDADE: O FETICHE DA MARCA MCDONALD'S NO BRASIL
}

Isleide Arruda Fontenelle EAESP-FGV

\begin{abstract}
RESUMO: Objetiva-se apresentar e discutir as relações atuais entre imagem e entretenimento a partir de pesquisas realizadas sobre a construção da imagem de marca McDonald's e sobre as modernas técnicas de marketing. Visando compreender porque nos tornamos consumidores de imagens, procurou-se recuperar, a partir da própria história do McDonald's, os acontecimentos econômicos, sociais, culturais, políticos, que teriam nos transformado em uma sociedade na qual "estar na imagem é existir". Embora trágica em seu sentido de fundo, essa perda da forma nos é compensada por imagens de diversão e felicidade que as marcas nos transmitem. Ao final, questiona-se o alcance global dessa promessa a partir de uma digressão sobre o Brasil: como a marca McDonald's nos fornece as imagens para uma certa constituição identitária; e o seu nome para um sentimento de permanência? Como falar de "identificação" com uma marca que, aparentemente, não teria uma relação histórica e cultural com o Brasil?
\end{abstract}

PALAVRAS-CHAVE: McDonald's; imagem; valor; entretenimento; fetichismo.

\section{ILLUSIONS OF MODERNITY: THE FETISH OF MCDONALD'S' BRAND IN BRAZIL}

ABSTRACT: This article presents and discusses the current relationship between image and entertainment, based on the results of research studies on the constitution of McDonald's' brand image all over the world and contemporary marketing. Aiming to understand why we have become image consumers, those studies tried to recover, based on McDonald's history, economical, social, cultural, and political events that have lead us towards an obsessed image society, in which, "being in the image is the same as existing". Although tragic in its bottom line, that inexistence of form is compensated to us by amusement and happiness images conveyed by the brands. Finally, the research questions the global reach of that promise, starting from a digression on Brazil: how does McDonald's' brand supply us images for a certain identity constitution; and its brand name for a permanence feeling? How is it possible to speak of "identification" with a brand that, seemingly, would not have a historical and cultural relationship with Brazil?

KEYWORDS: McDonald's, image, value, entertainment, fetishism.

A marca McDonald's é uma das maiores e mais poderosas marcas globais para consumo de massa. Presente em 119 países, com 31.129 lanchonetes e 48 milhões de clientes diários - dados de dezembro de 2005, disponíveis em www.mcdonalds.com.br -, a marca constitui-se na maior cadeia de fast food do mundo.

Mas, o que, de fato, vende o McDonald's? À primeira vista, essa pergunta parece tola, afinal, McDonald's é sinônimo de hambúrgueres. Entretanto, não é assim que a marca se vende e nem dessa maneira que quer se ver representada. Desde a década de 1950, Ray Kroc - o grande disseminador da marca McDonald's - já insistia que não estava no ramo de hambúrgueres, mas no show business (Kroc, 1987). O McDonald's não vende apenas pão, mas também circo, tornando-se o paradigma perfeito do que se denomina neste artigo de "sociedade das imagens".

E foi dessa maneira que o McDonald's foi tomado aqui: um objeto heurístico que pudesse se aproximar dos significados de uma realidade social permeada pelo predomínio das imagens, na forma como ela hoje se apresenta. Essa trajetória se iniciou a partir do doutorado em Sociologia, defendido em 2000, na Universidade de São Paulo - USP; e vem tendo continuidade, desde então, em duas formas de pesquisa: nos desdobramentos contemporâneos da "venda da imagem" - daquilo que, no marketing contemporâneo, se anuncia como a passagem da cultura do entretenimento para a cultura da experiência -; e nas especificidades dessas questões quando se pretende refletir sobre o Brasil.

Mais precisamente, no doutorado, percorreu-se a história do McDonald's desde sua fundação, em 1937, até o término da pesquisa, em 1999, tendo como principais fontes de pesquisa específicas sobre a empresa: biografias autorizadas e não autorizadas do seu fundador e da empresa; livros e artigos nacionais e internacionais; websites oficiais da empresa e de movimentos contrários; visita à sede da Cor-poração, ao museu da marca e à Universidade do Hambúrguer (Chicago-EUA); visitas a várias lanchonetes nos EUA e na Europa. Posteriormente, no pós-doutorado, concluído na Psicologia Social da PUC-SP, em 2004, realizou-se uma pesquisa bibliográfica e documental sobre a história do marketing e, a partir disso, buscou-se um aprofundamento teórico sobre os processos de subjetivação a partir de uma sociedade das imagens. Atualmente, realiza-se uma pesquisa focada na história da constituição do McDonald's no Brasil. 
Assim, este artigo está dividido em três partes. $\mathrm{Na}$ primeira, narra-se a história da construção da imagem do entretenimento através da história da criação do palhaço Ronald McDonald. Tal história permite reconstituir os primórdios da formação da cultura do entretenimento na sociedade americana e o papel fundamental que a televisão e a propaganda tiveram nisso. Na segunda parte, enfrentase o primeiro paradoxo da pesquisa: se os consumidores não acreditam na propaganda e nas suas promessas de diversão, por que, assim mesmo, consomem as imagens de entretenimento que tais marcas veiculam? Tal pergunta remete para uma digressão teórica acerca do "fetichismo das imagens" como um desdobramento contemporâneo do fetichismo da mercadoria. Aqui, chega-se à conclusão de que o consumo da marca utiliza-se das "imagens de marca" para uma certa formação identitária; e do "nome da marca" para um certo sentimento de permanência em meio ao fluxo intermitente de mudanças.

Mesmo assim, há um segundo paradoxo a enfrentar - o que é feito na parte três e final deste artigo: como afirmar que a marca fornece as imagens para uma certa constituição identitária e o seu nome para um sentimento de permanência quando se trata de relacionar o consumo de marcas estrangeiras - no caso, a marca McDonald's - ao Brasil? Como falar de "identificação" com uma marca que, aparentemente, não teria uma relação histórica e cultural com o Brasil? Neste ponto, serão apresentados alguns dados e perguntas, mais que respostas, sobre a especificidade brasileira no consumo de imagens e nomes de marca globais a fim de localizá-la nessa nova divisão social do consumo. Claro está que, no Brasil, a globalização funciona como uma "espécie de ideologia de segundo grau, que esconde e revela nossa realidade material poderosamente infletida pelos estímulos que vêm do centro" (Cevasco, 2001, p.15). Mas são justamente esse lugar que se ocupa e essa lógica da qual se participa que precisam ser desvendados.

\section{O Clown Ronald Mcdonald e a Busca pelo Fun}

De acordo com Fontenelle (2002), o McDonald's começou como um pequeno drive-in, na Califórnia, no final da década de 1930: uma época em que a produção em massa começava a aflorar, a partir de Henry Ford e seu modelo T, e o cinema se industrializava. Foi na junção desses dois movimentos que surgiu o drive-in, efeito de uma era na qual o automóvel tornava-se o grande ícone americano, fazendo do negócio de atendimento a consumidores dentro dos carros um ramo promissor.

Mas o McDonald's não foi o primeiro e nem o mais destacado drive-in de sua época. Um fato importante que selou o seu futuro como a maior cadeia de fast food do mundo foi a decisão dos dois irmãos McDonald originalmente, os proprietários do negócio, o qual foi adquirido depois por Ray Kroc - de fazerem uma ampla reforma em seu drive in e transformá-lo em uma lanchonete fast-food, no final da década de 1940. Dentre as inovações empreendidas estavam: substituição de todos os utensílios - talheres, copos, pratos - por embalagens descartáveis (era o início da indústria do descartável); eliminação do serviço de garçonetes - a partir de então os clientes teriam que sair dos seus carros e irem fazer o pedido no balcão -; e uma nova forma de produção e entrega dos sanduíches: a reformulação do cardápio, que passou a ser bastante enxuto, com os alimentos sendo preparados com base em uma linha de montagem.

O deslocamento de enfoque para a área de fast food foi essencial em uma época na qual emergia uma sociedade cada vez mais apressada. Não por acaso, buscando criar uma identificação do público com o seu negócio, os irmãos McDonald desenvolveram o primeiro personagem de marca da empresa: um boneco em forma de mestrecuca chamado Speedee, pois decidiram que a velocidade do serviço deveria ser o ponto fundamental a ser ressaltado no novo negócio. Some-se a isso, também, a previsibilidade do serviço e da comida, em uma América que buscava rapidez com a segurança do mesmo.

Até aqui, a imagem criada - o personagem Speedee era atrelada ao negócio. A velocidade e a previsibilidade do serviço e do produto era o que o McDonald's vendia e, de fato, queria vender. Isto porque, por essa época, tais atributos faziam, de fato, a diferença em meio à concorrência. É somente na década de 1960, quando o negócio já passara para as mãos de Ray Kroc, que se dá início o descolamento entre o produto, o serviço e a imagem de marca e começa a associação entre imagem de marca, personagem de marca e entretenimento, com a criação do palhaço Ronald McDonald e um composto de arquitetura e design que se atrelasse ao objetivo de vender diversão.

Mas, quem é Ronald McDonald? De acordo com sua "biografia", veiculada pela própria companhia, Ronald é um palhaço inteligente e sensível que adora hambúrgueres, brincadeiras e crianças. Ronald McDonald é um super astro e o porta-voz oficial da companhia junto às crianças, tornando-se o palhaço mais publicizado do mundo (Fishwick, 1983).

Ronald inicia sua história em 1960, quando um franqueado da cadeia, em Washington D.C., decidiu promover sua lanchonete com um anúncio televisivo, veículo ainda pouco utilizado para promover restaurantes, embora a televisão já estivesse se tornando o grande elo entre um produto e o seu consumidor em outros setores comerciais. Nessa época, ainda não havia um plano nacional de marketing para o McDonald's e cada franquia local estabelecia os critérios com os quais gostaria de atrair o seu público. No entanto, a ênfase de Ray Kroc em captar a atenção das famílias, especialmente crianças - a famosa geração baby-boom - era bastante conhecida por toda a 
rede. E, para atingir as crianças, a televisão estava se mostrando um veículo perfeito.

Os shows infantis, naquela época, estavam entre os programas com maior audiência, especialmente "O Circo do Bozo", divulgado por uma rede em Washington, filiada à cadeia de televisão NBC. O franqueado do McDonald's tornou-se um dos patrocinadores do programa, vislumbrando nele o veículo onde poderia atingir o seu público-alvo: as crianças. Assim, o McDonald's começou a aparecer na TV através do palhaço Bozo, que anunciava os seus produtos de uma forma nada sutil: apelando diretamente às crianças a pedir ao papai e à mamãe para leválas ao McDonald's (Love,1995). Bozo fez tanto sucesso que passou a ser convidado a participar da inauguração das novas lojas McDonald's em Washington, levando sempre à formação de filas enormes de pais e crianças em frente aos restaurantes (Love,1995).

Mas, em 1963, a emissora retirou o programa do ar, alegando uma queda de audiência, e o franqueado perdeu aquele que se tornara seu grande porta-voz junto às crianças. Sem poder produzir sozinho o programa, o proprietário da loja em Washington decidiu criar um palhaço próprio e colocá-lo em propagandas televisivas, usando o mesmo ator que havia personificado o palhaço Bozo, William Scott. Naquela época, o visual do palhaço era modelado por produtos do próprio McDonald's:

O chapéu era uma bandeja com um hambúrguer de isopor, um saquinho de batatas fritas e um milk shake. Os sapatos tinham a forma de pãezinhos e o nariz era feito de um copo do McDonald's. O cinto era um hambúrguer de isopor e no vídeo o palhaço retirava, num passe de mágica, hambúrgueres do cinto. (Love, 1995, p.274)

O nome - Ronald - surgiu por acaso: simplesmente rimava com McDonald. Sua primeira aparição televisiva foi em 1963. Mas o palhaço só veio a ser adotado nacionalmente pela companhia numa situação que seu biógrafo, John Love, considerou como emergencial. Em 1965, o McDonald's se viu diante da grande oportunidade de participar da Parada Macy's do "Dia de Ação de Graças", comemorado em 25 de novembro, na cidade de Nova York - uma data especial para os americanos e muito popular. Foi aí que a companhia fez sua primeira compra, nacional, de mídia televisiva. Mas, quando essa oportunidade apareceu, faltavam apenas algumas semanas para a Parada, o que forçou a companhia a adotar os comerciais que a D'Arcy havia produzido um ano antes para os franqueados locais, que destacavam o palhaço Ronald McDonald (Love, 1995).

A aparência física de Ronald também foi modificada pela agência publicitária, tirando-lhe aquela roupagem extremamente comercial, com os produtos do McDonald's, e lhe dando características de um verdadeiro clown: Ronald McDonald tornou-se um descendente do matreiro e gracioso Harlequim e do desajeitado Pierrot os ajudantes cômicos da comédia - que se vestem de calças e blusas frouxas e chapéu de abas largas, traje que persiste até hoje como característico de muitos palhaços (Fishwick, 1983).

Com Ronald, as propagandas veiculadas pela D’Arcy se transformaram na primeira campanha nacional da companhia, cujo tema foi “o McDonald's é o seu lugar", enfatizando o restaurante como um espaço de diversão, e não apenas um lugar para se comer hambúrguer, num momento que revelava os contornos de uma sociedade cada vez mais inclinada para lugares que pudessem transmitir uma "experiência" de diversão. Embora Kroc, desde o início, insistisse na imagem do McDonald's como um "show", a companhia precisava de algo que representasse essa imagem. O palhaço começara a se mostrar perfeito para isso.

E foi assim que, desde 1965, o palhaço tornou-se nacional - posteriormente internacional - e o símbolo vivo do McDonald's. Ao contrário de Speedee ou dos arcos dourados, ele não foi utilizado como parte do exterior do edifício ou em letreiros em frente às lojas, já que estava reservado para a TV, embora, desde o início, ele tenha sido "materializado" em aparições públicas; como um gigante boneco inflável no telhado de algumas lojas maiores; em bonecos de tamanho natural na entrada de algumas lojas, dando as boas vindas aos consumidores; em outdoors e em dezenas de retratos e pequenos bonecos no interior dos restaurantes, especialmente nos salões que reproduzem a McDonaldland.

É nesse sentido que o palhaço é tomado como uma figura emblemática de uma era marcada pela busca da diversão a qualquer custo. Ronald surge no interior de uma sociedade já plasmada pela cultura do consumo e no tempo em que a televisão atingia o seu auge, exatamente em função da popularização do seu uso. Em 1960, viviase o emergir da "cultura do lazer", que está diretamente relacionada a uma redução do tempo de trabalho: nessa década, a semana de trabalho nos Estados Unidos passa a ser de 37 horas, quando, um século antes, era quase o dobro. O tempo livre passa a ser, então, um tempo ganho sobre o trabalho, mas "é um tempo que se diferencia do tempo das festas, característico do antigo modo de vida" (Morin, 1990, p.67). Não é de se admirar que, passado um século da Revolução Industrial, a maneira com que os homens passam a lidar com o seu tempo livre seja profundamente influenciada pelas mudanças provocadas por essa mesma Revolução.

É assim que Edgar Morin nos mostra como o tempo das festas coletivas foi corroído pela moderna organização social que operou o emprego de um novo tempo livre pausa para o almoço, o anoitecer, o fim-de-semana, as 
férias -, mais ampliado do que o vivido no auge do processo de industrialização; porém, mais estável e rotineiro do que o lazer pré-industrial. E é simultaneamente ao vazio deixado pela redução do tempo do trabalho que a cultura de massa trata de preenchê-lo através das conquistas efetuadas pela Revolução Industrial: os produtos para consumo, as viagens de automóveis, a televisão na sala de jantar; enfim, uma nova forma de bem-estar proporcionada pela vida consumista.

Em meio a essas conquistas, o lazer moderno surge "como o tecido mesmo da vida pessoal, o centro onde o homem procura se afirmar enquanto indivíduo privado", levando a cultura de massa a ser considerada essencialmente sob a ótica de uma "ética do lazer", em detrimento de uma "ética do trabalho" (Morin, 1990, p.67). No interior dessa nova ética, o divertimento passa a ganhar contornos precisos: passar o tempo - passatempo -, seja de que forma for, até mesmo podendo-se estar em outro lugar, mesmo sem sair de casa, no interior da vida privada. Isso se tornou possível graças à televisão.

Não é à toa, então, que o palhaço Ronald McDonald seja cria da televisão. Ele surgiu na TV e para a TV: reflexo de um tempo no qual esse meio estava se tornando o grande circo da moderna era eletrônica que, a essa altura, já podia reproduzir, com realismo, as luzes e cores da nossa realidade cada vez mais estetizada.

Conforme visto, a propaganda do McDonald's já surge no interior de um novo modelo de anúncio televisivo que, embora usado em outros setores, era inédito no meio dofast-food: ao invés de anunciar diretamente o produto e procurar convencer o consumidor dos seus atributos e benefícios, apela-se para uma história, uma narrativa, um filme onde se procura retratar situações nas quais a marca pode ser associada positivamente com um certo modo de vida. É interessante atentar para o fato de que os anúncios das diferentes marcas passaram a ser veiculados em forma de entretenimento. Daí porque, neste caso, o palhaço Ronald é uma espécie de paradigma desse tipo de propaganda que apela para a diversão, voltada para um espectador ávido por entretenimento.

No caso específico do McDonald's, os comerciais buscaram retratar um ideal de diversão no qual as lanchonetes se apresentavam como lugares ideais para isso. Mas o que faria uma sociedade, em uma determinada época, acreditar que uma ida a uma lanchonete de fast food fosse, de fato, uma forma de diversão? Não se trata de apelar para a explicação simplista de que a propaganda teria o poder de seduzir pelas imagens comerciais, levando o telespectador a imergir na ilusão de suas promessas. Os dados da pesquisa sugerem a constatação de que se trata de um "jogo de faz de conta", do qual o consumidor participa conhecendo suas regras. Esse é o paradoxo do funcionamento da marca: pensar a propaganda não como farsa, mas como uma verdade sobre a época na qual ela emerge. Assumir que o que conta, na verdade, não são as mentiras que ela veicula, mas entender porque as pessoas, que sabem que isso tudo é mentira, "agem como se não soubessem".

\section{O Jogo do Faz-de-Conta: Consumir para Existir}

A variável teórica que fundamentou a pesquisa - a fim de compreender porque a sociedade contemporânea sabe que consome imagens, mas age como se não soubesse - foi a do "fetichismo das imagens" enquanto um desdobramento contemporâneo do "fetichismo da mercadoria”, elaborado por Karl Marx.

A fim de desvendar aquela que foi denominada de "sociedade das imagens", através de um estudo do consumo de marcas publicitárias - tomando a marca McDonald's como paradigma -, chegou-se à constatação de que vivemos um recrudescimento do fetichismo, conseqüência de um novo estágio do capitalismo movido por aceleração e descartabilidade, ao qual, por sua vez, corresponde essa forma social definida como "sociedade das imagens".

Partindo-se de uma análise interna ao funcionamento da marca publicitária, chegou-se à conclusão de que a marca tornou-se uma "ilusão de forma" numa sociedade que está perdendo a sua forma. Para poder determinar historicamente esse vazio, foi necessário compreender as profundas mudanças - tecnológicas, econômicas, sociais e culturais que levaram a essa implosão das formas, através da história de uma marca publicitária específica, qual seja, a marca "McDonad's". Assim, a história da constituição dessa marca tornou-se, paradigmaticamente, a superfície através da qual emergiram os principais acontecimentos que forjaram a atual "sociedade das imagens". Desse modo, seguindo a periodização histórica da marca McDonald's no interior da sociedade americana, desde a sua fundação, ainda nos anos 1930, até os nossos dias, acabou-se por resgatar uma espécie de "gênese" da sociedade do consumo, que resultou na atual sociedade das imagens.

Foi dessa análise, interna à própria marca, que ficou muito clara a tese de que a cultura tornou-se descartável, na medida em que ela tornou-se a principal mercadoria no capitalismo contemporâneo; e a mercadoria, em sua própria essência, é descartável. Uma explicação mais detalhada sobre as bases estruturais da descartabilidade da mercadoria pode ser encontrada em Fontenelle (2002). Por ora, é mais pertinente ressaltar que a idéia de cultura, aqui posta, não se refere, apenas, ao domínio da "produção cultural" no seu sentido estrito, mas também à sua materialidade, ou seja, à relação visceral entre o mundo da produção material e suas formas de representação. Hoje, isso está cada vez mais imbricado, levando alguns autores - como Jameson (2001) e Eagleton (1993) - a defenderem a tese de uma fusão do econômico com o cultural, o que pode ser exemplificado na expressão já tão gasta e tão mal compreendida chamada "cultura de consumo".

Nesse sentido, o desafio foi retomar o conceito de "cultura de consumo", através de como isso se efetiva na 
realidade social. Para tanto, foi necessário relacionar toda a história da construção da marca McDonald's com o que, também, se tornou convencionado como "cultura do fastfood', na qual, mais importante que vender hambúrgueres, seria vender "atitudes" ligadas a hambúrgueres, vender um modo de vida enquanto entretenimento, "espetáculo".

Nessa relação entre o produto vendido pelo McDonald's - comida rápida - com todo um modo de vida embalado para consumo que se constituiu a partir da emergência daquilo que foi denominado de "tempo do fast-food", percebe-se, claramente, como o novo paradigma da produção capitalista tornou-se a "indústria cultural". Esse termo é usado no sentido original atribuído por Adorno \& Horkheimer (1985), qual seja, não apenas no sentido da dimensão artística enquanto um dos domínios das representações culturais, mas no de uma "cultura moderna", cuja dimensão material da vida foi organizada sob a forma capital.

Segundo os autores acima citados, estaríamos vivendo um processo de "fetichização total da cultura", fato este já analisado por eles a partir de 1930 e, não por acaso, especialmente a partir da análise da propaganda de massas nos Estados Unidos. De lá para cá, esse processo se intensificou, marcado especialmente por uma marcha intensa e ininterrupta do sentido do tempo e que, mais especificamente a partir das últimas duas décadas, começou a implodir todas as formas produzidas. Por "formas produzidas" entendam-se as diversas "simulações de realidade" que a época moderna tratou de fabricar para dar forma ao novo mundo que se descortinava após a rígida ordem feudal, sendo capaz de forjar uma "cultura da ordem", com instituições, valores e crenças que pareciam inabaláveis até pouco tempo.

Hoje, na ausência de formas mais consistentes e, também, mais permanentes, foram perdidas as referências que, de certa maneira, marcavam nossos lugares no mundo. Daí porque a marca publicitária se oferece para ocupar esse lugar, especialmente porque ela é um sintoma, por excelência, daquilo que provocou esse esvaziamento: um novo estágio do capitalismo marcado por aceleração e descartabilidade permanentes. A marca torna-se, portanto, um fetiche, pois é uma maneira de preenchimento desse vazio, algo do qual nos utilizamos para dar forma, contorno, enfim, fecharmos uma maneira de definirmos o mundo, a vida, as pessoas e a nós mesmos.

Mas esse processo de fetichização não é feito à revelia do sujeito, como se pôde verificar através da análise de uma das principais ferramentas de que a marca dispõe para se constituir e se manter: a publicidade. Por "publicidade", entenda-se a veiculação "gratuita" da marca na "mídia de notícias" ou, de outro modo, a inserção de uma marca na "mídia-realidade", de maneira que ela se diferencie claramente de um anúncio comercial pago pela detentora da marca (a chamada "propaganda"), mas que, claro, requer um trabalho cada vez mais bem pago de "relações públicas". A idéia é de que a marca seja veiculada em meio às notícias "verdadeiras, reais"; e se imiscua de tal maneira a essas notícias que acabe, ela mesma, por criar uma "nova realidade". E isso pode ser facilmente comprovado na análise mais aprofundada da marca McDonald's - a partir de sua constituição na sociedade americana -, bem como de muitas outras marcas globais.

Há, assim, uma relação visceral entre publicidade e mídia, na qual esta última assume o lugar de "suposto saber", levando cada um a constatar que "estar na imagem é existir". Daí porque se assume a tese de que o sujeito que consome imagens sabe que elas são ilusórias, mas age como se não soubesse. Este se torna um sujeito marcado o tempo inteiro pela necessidade da performance. Interessa-lhe as máscaras, os disfarces, a capacidade de exercer diferentes papéis, o tempo inteiro, para poder ser captado pelo outro enquanto uma imagem de si mesmo.

Esse sujeito que "sabe, mas..." também marca um ponto de inflexão com o sujeito moderno. Certamente, desde a modernidade, nossa relação com a verdade já havia se modi-ficado: elas já não eram mais eternas, imutáveis. Mas, como já foi dito antes, a época moderna soube construir grandes "simulações de verdades" coletivas que nortearam nossas vidas desde então. Hoje, o que há é pura fluidez e um deslocamento incessante de formas que nos ameaçam com a face terrível do vazio. Essa aceleração total torna o próprio fetiche "excessivo a qualquer forma", "a estrutura de uma auto-produção incessante" a fim de se evitar que cheguemos à essência radical da forma mercadoria: o monstruoso, o sem-forma (Eagleton, 1993, pp.158-159). É essa vacuidade social que leva o sujeito contemporâneo a estar numa busca permanente por se construir e se reconstruir o tempo todo, tentando dar conta dos horizontes que se abrem e que ele não consegue mais nomear.

Que sujeito é esse que sabe, mas age como se não soubesse? Seria o sujeito da "razão cínica" de Sloterdijk (1988), destituído de qualquer forma de ilusão, levado ao paradoxo de uma "falsa consciência esclarecida"? Se assumir-mos a invalidez da tese da "falsa representação da realidade", concebida por Adorno (1973), não podemos nos contentar com a argumentação.

Questionando, justamente, essa tese da "razão cínica", o filósofo e sociólogo esloveno Slavoj Zizek nos ajuda a compreender o paradoxo do "sabe, mas..." a partir da noção de "fantasia ideológica", tomando o estatuto de uma ilusão inconsciente que se apresenta no "fazer", ou seja; no funcionamento sintomal da ideologia, a ilusão fica do lado do saber, enquanto a fantasia ideológica funciona como uma ilusão, um erro que estrutura a própria realidade, que determina nosso fazer, nossa atividade (Zizek, 1992). 
No caso da marca publicitária, por exemplo, poderíamos afirmar que o sujeito que consome a marca sabendo que ela ilusória, assim o faz movido por uma ilusão inconsciente que se materializa na sua ação de consumir tais imagens; o que, certamente, vela o terrível sofrimento psíquico a que está submetido para dar conta, continuamente, de um imperativo de consumo movido pelo culto à existência na imagem.

Essa forma de existência - ou "política de vida", como a ela se refere Bauman - deriva de um código muito particular: da pragmática do comprar. Precisamos consumir e sermos consumidos para existirmos enquanto imagens. E a idéia de fundo, ainda segundo Bauman, é a de que o mercado torne-se o veículo que promove identidades, na medida em que:

(...) os símbolos de estilos de vida são endossados por pessoas com autoridade e pela informação de que um número impressionante de pessoas o aprova. A aceitação social não precisa portanto ser negociada - desde o início ela é, por assim dizer, "inerente" ao produto posto no mercado (Bauman, 1999, p.217).

Trata-se, portanto, de uma "nova organização social da ilusão", na qual categorias como cultura e identidade ganham novas dimensões. Diante de tal conclusão - baseada em pesquisas de cunho histórico (a constituição da marca McDonald's nos Estados Unidos e sua permanência até os dias atuais) e teórico (a questão do fetichismo das imagens na contemporaneidade) - restou um aparente paradoxo a partir do qual os resultados dessa pesquisa passaram a ser interpelados: como afirmar que a marca nos fornece as imagens para uma certa constituição identitária e o seu nome para um sentimento de permanência quando se trata de relacionar o consumo de marcas estrangeiras - no caso, a marca McDonald's - ao Brasil? Como falar de "identificação" com uma marca que, aparentemente, não teria uma relação histórica, cultural, com o Brasil?

De fato, quando se trata de trazer essas categorias para o campo específico da realidade brasileira, é preciso compreender como elas se deslocam dos espaços sócioculturais a partir dos quais foram construídas para relacioná-las ao que foi produzido a partir da própria realidade brasileira. Como trabalhar a difícil imbricação entre o cultural e o modelo de desenvolvimento que tem sua lógica própria no cenário brasileiro?

\section{McDonald's no Brasil: a ilusão necessária?}

A marca McDonald's chegou ao Brasil em 1979 e a porta de entrada foi o famoso bairro de Copacabana, na cidade do Rio de Janeiro. Por essa época, encerrava-se o chamado ciclo desenvolvimentista brasileiro (1950-1980), quando se deu início ao que ficou conhecido por "década perdida”. Não para o McDonald's: a partir da década de 1980, a rede começou a se expandir geometricamente pelo país, abrindo, em 1985, a maior loja McDonald's da América Latina (em São Paulo) e contando, no final de 2005, com 1.200 pontos de vendas espalhados em quase todos os estados brasileiros, servindo diariamente a um milhão e meio de pessoas - dados do McDonald's do Brasil, em dez/2005.

Quando aportou no Brasil, a primeira imagem que o McDonald's representou não foi a do entretenimento para as massas - que era a que ainda vigorava em solo americano -, foi a de modernidade, de uma experiência de desenvolvimento, de "cultura de ponta". Enquanto nos EUA da década de 1970 o McDonald's se reinventou como diversão barata para as famílias de classe média americana, no Brasil, em seus primórdios, o McDonald's era objeto de desejo de uma juventude abastada, na região mais cosmopolita do Brasil, até mesmo devido ao preço de seus sanduíches, até hoje incrivelmente alto, se comparado com o poder de compra do brasileiro.

As primeiras propagandas do McDonald's no Brasil não visaram vender a imagem de uma ida a um lugar de felicidade, como foram assim apresentadas nos EUA, mas, pelo contrário, tinham a função de "educar para esse consumo tão moderno", de "civilizar" e, até muito recentemente, ainda se observavam propagandas que têm essa função de treinar para o consumo, embora isso não seja feito de forma escolar, mas divertida, como a propaganda que ensina o que é um Big Mac, a partir dos ingredientes que ele contêm. Isso é feito a partir de música e letra dois hambúrgueres, alface, queijo, molho especial, cebola, pickles, num pão com gergelim -, tentando ser cantada por vários tipos de consumidores brasileiros que se atrapalham com a quantidade de palavras, muitas das quais até então desconhecidas do nosso dialeto.

À primeira vista, essa imagem pode ser entendida como resultado natural do subdesenvolvimento que nos levou a nos mirarmos sempre no espelho do outro: antes, no espelho europeu; e, desde meados do século XX, no americano, que teria tornado nossa maneira de ser e de viver uma cópia do "american way of life". Essa realidade nos configurou, desde a colonização, como mercado consumidor e fornecedor de mão-de-obra, mas sempre com a promessa de integração dos colonizadores e colonizados em um modelo político e econômico universal. Tal promessa

aparece como uma espécie de tragédia originária e constitutiva das ex-colônias, tendo-lhes imprimido o estigma da ambivalência desde o nascimento e que, ainda hoje, condiciona o olhar do Novo Mundo sobre si mesmo, dando-lhe uma conotação de estranheza, de exterioridade e de inautenticidade, por colocá-lo sempre no registro da avaliação, do julgamento e da comparação com o mundo do colonizador (Dymetman, 2005). 
Fosse na ótica evolucionista, onde sempre assumimos o lugar do exótico, do selvagem, do irredutível à lógica do progresso; fosse na ótica desenvolvimentista, que vigorava com intensidade nos países latinos ainda na década de 1970, cuja leitura de nosso "estado de arte" era a do atraso ainda à procura do progresso prometido, ou melhor, já em andamento, do qual a chegada do McDonald's era um exemplar por excelência.

Mas foi, exatamente nessa década de 1970, que um clássico de um autor brasileiro, o sociólogo Francisco de Oliveira, tratou de desvelar essa lógica que ele denominou "razão dualista" (Oliveira, 1972), no sentido de mostrar como o atraso, considerado como obstáculo ao desenvolvimento almejado, era, na verdade, a condição por excelência desse desenvolvimento. Em outras palavras, Oliveira tratou de mostrar que se tratava de uma "revolução conservadora", com uma mudança conjuntural vedando a transformação estrutural (Oliveira, 1972).

No que diz respeito à nossa especificidade cultural, ou seja, a um "olhar para quem somos", essa razão dualista se apresenta no pensamento brasileiro a partir da fórmula célebre de Paulo Emílio Salles Gomes (1980), de que "não somos europeus nem americanos do norte, mas destituídos de cultura original, nada nos é estrangeiro, pois tudo o é. A penosa construção de nós mesmos se desenvolve na dialética rarefeita entre o não ser e o ser outro" (Gomes, 1980, p.77). Essa imagem foi interiorizada, tornando-se conteúdo identitário e coletivo de pertencimento, que se reproduz como experiência nacional.

Nada mais exemplar do que nossa compra dessa "miragem" de entretenimento das terras ianques. Afinal, nos EUA, o McDonald's já se apresentava como uma configuração re-significada de seu negócio: de vender fast food em uma sociedade marcada pela pressa para vender aquele que, segundo o crítico cultural norteamericano Neal Gabler, teria se tornado o valor número um da sociedade americana, qual seja, o entretenimento. A reconstituição histórica feita por Gabler (1999) para explicar porque o entretenimento foi a mais importante transformação cultural dos Estados Unidos no século XX, ajuda-nos a entender, a partir de suas raízes históricas, a proeza que o McDonald's teve em associar sua imagem ao entretenimento. Afinal, como uma ida a uma burocrática, fordista loja de hambúrgueres pôde ser identificada como uma experiência de diversão?

Remontando a história do seu país do início do século XIX, Gabler mostra como, desde lá, já "havia alguma coisa de errada com os Estados Unidos": uma ânsia por viver em um estado de felicidade ilusória, um gosto pela estridência, pelo exagero, que chocava os ilustres e requintados visitantes europeus. Desde lá, segundo Gabler, os americanos queriam diversão: "gratificação e não edificação, transigência e não transcendência, reação e não contemplação, escape, em vez de submissão às instruções morais" (Gabler, 1999, p.23).

Ainda está para ser feita essa reconstituição histórica do entretenimento em terras brasileiras, mas é possível, pelo menos, apontar que, no século XIX, o modelo que aqui vingava como de modernidade era o europeu. Nesse aspecto, o ideal de lazer que cercava esse modelo bebia no padrão europeu, sobretudo francês, de fruir de uma cultura mais refinada. Daí ser uma ironia dessa nossa história que o primeiro McDonald's tenha aportado no Brasil, exatamente, naquela que era a mais européia e afrancesada capital brasileira: o Rio de Janeiro.

Mas, nessa passagem de um modelo europeu para o modelo americano, nem tudo é pura imitação. De uma certa maneira, o brasileiro antropofagiza esse modelo quando, por exemplo, a propaganda o mostra rindo de si mesmo por não saber falar palavras que lhe são ainda tão estranhas. Coisa que o McDonald's soube compreender muito bem e que, talvez, explique porque conseguiu se tornar a marca de fast food por excelência no Brasil. Retomando a questão que norteou esta parte final do artigo, o que se está querendo afirmar com isso é que não é qualquer marca estrangeira que nos oferece a imagem identitária e a segurança do nome. Há uma certa especificidade na maneira de propor isso que fez com que o McDonald's conseguisse o que outras marcas de fast food não conseguiram; as quais, pelo contrário, até fracassaram em se fixar no Brasil - como a Pizza Hut, a Kentucky Fried Chicken (KFC), a Subway, dentre outras.

É interessante, nesse sentido, acompanhar a evolução da mesma propaganda - sobre cantar o que contém um Big Mac - vinte e cinco anos depois da entrada do McDonald's no Brasil: agora, é exibida uma nova propaganda, na qual os brasileiros já sabem cantar a música e já cantam em seu ritmo próprio, que reproduz os vários estilos musicais do país: o forró, o funk, o samba, a bossa nova. A propaganda evidencia, simbolicamente, o quanto a imagem de entretenimento que o McDonald's vendia nos EUA, quando por ocasião de sua entrada no Brasil o pão com o circo, as cores, o palhaço Ronald -, já foi completamente assimilada como um estilo de ser e de se divertir do brasileiro.

No Brasil de 2005, enquanto o ideal de entretenimento se fixou e o McDonald's continua crescendo a passos largos - só em 2005, a Corporação cresceu 13\%, enquanto o crescimento do país nesse ano foi de 2,3\%; tendo fechado o ano com um faturamento em torno de U\$ 875 milhões -, a promessa de modernidade do país não se concretizou. Vinte e cinco anos depois da chegada do McDonald's ao Brasil, o mesmo autor da "Crítica à Razão Dualista", o já citado Francisco de Oliveira, atualiza sua leitura do Brasil e constata que nos tornamos um assustador ornitorrinco no qual o "trabalho abstrato virtual" (serviços) mostra-se em suas formas exóticas, onde 
"o trabalho aparece como diversão, entretenimento, comunidade entre trabalhadores e consumidores: nos shopping centers"; e, por outro lado, no crescimento infernal do trabalho informal, seja na venda de marcas de bebidas e refrigerantes às portas dos estádios em dias de shows musicais ou jogos de futebol ou em "tapetes de quinquilharias (...) um bazar multiforme onde a cópia pobre do bem de consumo de alto nível é horrivelmente kitsch (...)" (Oliveira, 2003, p.142).

Em outras palavras, somos um monstro feito de colagens de cacos de sonhos que se despedaçaram e que se manifestam na falsa promessa do progresso - através do consumo de primeiro mundo -, com a persistência do nosso eterno atraso, através do trabalho informal, por exemplo. Nesse cenário, o McDonald's já é portador de um novo modelo de desenvolvimento, resultante da terceira revolução industrial. Em um momento no qual começam a se desenhar os contornos da "economia do acesso" e que já se aponta que a mercadoria dessa nova economia será, por excelência, a "experiência", é a lanchonete de fast food que nos "educa" para esse novo cenário, vendendo acesso e experiência.

Trata-se da "McInternet", um projeto inovador da rede, o primeiro desse tipo no mundo, que começou em caráter experimental em 2001, quando as lanchonetes McDonald's passaram a oferecer computadores com acesso gratuito à Internet. Não fosse já surpreendente a maneira como o McDonald's está se reinventando na periferia do mundo, através do que há de mais moderno em termos da revolução da informação, isso ainda está sendo feito a partir de novas formas de gestão, baseadas no discurso da responsabilidade social. A par do mapa da exclusão digital do Brasil, onde apenas $12 \%$ dos brasileiros têm computadores em suas residências e pouco mais de $8 \%$ deles estão conectados à Internet (Neri, 2003), a alta direção da empresa decidiu nomear o projeto da McInternet como sendo a contribuição do McDonald's para favorecer a inclusão digital no País e seus diferenciais de modernidade.

Inclusão digital como commodity no templo do entretenimento. Uma façanha e tanto em um país que caminha mal em termos da modernidade almejada, mas que, com um sinal invertido, parece nos garantir que continuamos na vanguarda, enquanto um laboratório "do famigerado desenvolvimento desigual e combinado de um capitalismo que parece continuar o mesmo" (Arantes, 2004, p.77). Como imagem ideal dessa situação, poderse-ia lançar mão do quadro atual do nosso processo de modernização que o historiador brasileiro Francisco Alambert montou: a pas-sagem da nossa imagem de "Jeca Tatu" o personagem criado pelo escritor brasileiro Monteiro Lobato como exemplo acabado de nossa imagem de "homem cordial" - para "Homer Simpson", o "joãoninguém do desenho da TV norte-americana (...) nosso rosto e nosso destino global para consumo próprio" (Alambert, 2005).

Mas, como afirma o próprio Alambert, os Simpsons "descendem do melhor que a televisão norte-americana criou como crítica radical de sua auto-imagem heróica". Nesse sentido, não cai bem para vender os "sanduíches de fantasia" que a marca McDonald's nos oferece. Lanço mão de uma frase de Neal Gabler, de que o entretenimento sempre prometeu "nos afastar dos problemas diários e permitir que escapássemos das atribulações da vida" (Gabler, 1999, p. 13), para refazer a imagem de Alambert: talvez pudéssemos pensar que somos a mistura de "Jeca Tatu" com o palhaço Ronald McDonald.

Na linguagem publicitária, Ronald tornou-se a "personalidade de marca" do McDonald's. E o que seria uma "personalidade de marca"? Seria pensar a marca como se fosse uma pessoa; ou seja, personifica-se a marca e, por conseqüência, o produto, através de associações do tipo: se essa marca fosse uma pessoa, ela seria alegre, divertida, carinhosa, amigável, etc. Segundo Randazzo (1997), é a imagem do usuário que mais contribui para a construção da personalidade da marca. Em uma economia imaterial como a contemporânea, em que os produtores foram substituídos pelos consumidores, são eles que produzem commodities como a imagem da marca. E, ao mesmo tempo, como um reflexo espectral, a imagem do usuário representa o tipo de pessoa que uma determinada marca deseja refletir, tendo em vista o seu público alvo. Considerando tal estratégia, podemos concluir que Ronald reflete o consumidor do McDonald's: um palhaço, e o que ele, simbolicamente, representa: o circo, a alegria, a diversão; enfim, todo o universo mitológico que está associado à figura do palhaço.

O clown Ronald McDonald pode ser tomado como a imagem invertida dos Simpsons enquanto uma América profundamente idealizada, fundada na busca pelo fun que o cinema de Hollywood, os parques da Disney e a marca de fast food retratam tão bem. No caso brasileiro, essa imagem é interiorizada junto com a experiência do atraso: ainda somos Jeca Tatu, mas a roupagem é nova. É por isso que é possível afirmar que, de fato, a imagem e o nome da marca McDonald's nos oferece a ilusão necessária que desejamos consumir.

\section{Referências}

Adorno, T.W. \& Horkheimer, M. (1985). Dialética do Esclarecimento: fragmentos filosóficos. Rio de Janeiro: Jorge Zahar.

Adorno, T.W. \& Horkheimer, M. (1973). Temas Básicos da Sociologia. São Paulo: Cultrix. 
Alambert, F. (2005, 11 de dezembro). De Jeca Tatu a Homer Simpson. Jornal Folha de São Paulo. p.3 (Caderno Mais!)

Arantes, P. (2004). Zero à Esquerda. São Paulo: Conrad.

Bauman, Z. (1999). Modernidade e Ambivalência. Rio de Janeiro: Jorge Zahar.

Cevasco, M.E. (2001). Prefácio. Em F. Jameson (Ed.), A cultura do dinheiro: ensaios sobre a globalização. Petrópolis, RJ: Vozes.

Dymetman, A. (2005). Excessos da modernidade: Exceção e razão. Em Associação Nacional dos Programas de Pós-graduação em Ciências Sociais (Ed.), XXIX Encontro Anual da ANPOCS. Caxambu-MG: ANPOCS. Retirado do CD-ROM XXIX Encontro Anual da ANPOCS, março 16, 2006.

Eagleton, T. (1993). A Ideologia da Estética. Rio de Janeiro: Jorge Zahar.

Fishwick, M. (1983). Introduction. Em M. Fishwick. (Ed.), Ronald Revisited: the world of Ronald McDonald (pp.1-14). Ohio: Bowling Green University Popular Press.

Fontenelle, Isleide A.(2002). O nome da marca: McDonald's, fetichismo e cultura descartável. São Paulo: Boitempo.

Gabler, N. (1999). Vida-O Filme: como o entretenimento conquistou a realidade. São Paulo, Companhia das Letras.

Gomes, Paulo E.S. (1980). Cinema, trajetória no subdesenvolvido. Rio de Janeiro: Paz e Terra.

Kroc, R. (1987). Griding it Out: The making of McDonald's. SL: St. Martin's.

Love, J.F. (1995). McDonald's: behind the arches. New York: Bantam Book.

Morin, E. (1990). Cultura de Massas no Século XX: o espírito do tempo. Rio de Janeiro: Forense Universitária.

Neri, M. (2003, maio). O Mapa da Exclusão Digital. Conjuntura Econômica. p.70-73.

Oliveira, F. (1972). A Economia brasileira: Crítica à razão dualista. Estudos Cebrap, São Paulo.

Oliveira, F. (2003). Crítica à razão dualista - O Ornitorrinco. São Paulo: Boitempo.
Randazzo, S. (1997). A criação de mitos na publicidade: Como publicitários usam o poder do mito e do simbolismo para criar marcas de sucesso. Rio de Janeiro: Rocco.

Sloterdijk, P. (1988). The Critique of Cynical Reason. Minneapolis: University of Minnesota Press.

Zizek, S. (1992). Eles não sabem o que fazem: o sublime objeto da ideologia . Rio de Janeiro: Jorge Zahar.

Isleide Arruda Fontenelle é professora assistente da EAESP-FGV, Departamento de Fundamentos Sociais e Jurídicos da Administração - Área: Psicologia. Graduada em psicologia, com mestrado em sociologia e doutorado em sociologia pela USP. Possui também pós-doutorado em psicologia social pela PUC-SP.

Atualmente, é professora da graduação e pósgraduação da EAESP-FGV na área de psicologia do Departamento de Fundamentos Sociais e Jurídicos da Administração.

É autora do livro "O nome da marca: McDonald's, fetichismo e cultura descartável". Endereço: Av. 9 de Julho, 2029. São Paulo, SP - Brasil; CEP: 01313-902.

isleide@ fgvsp.br

\section{Ilusões de modernidade: $o$ fetiche da marca McDonald's no Brasil}

Isleide Arruda Fontenelle

Recebido: 20/03/2006

$1^{\text {a }}$ Revisão: 08/06/2006

Aceite final: 20/06/2006 